ISSN 2071-1050

www.mdpi.com/journal/sustainability

Article

\title{
Representation of Ecodesign Practice: International Comparison of Industrial Design Consultancies
}

\author{
Johannes Behrisch $^{1, *}$, Mariano Ramirez ${ }^{2}$ and Damien Giurco ${ }^{1}$ \\ 1 Institute for Sustainable Futures, University of Technology, Level 11, UTS Building 10, 235 Jones \\ Street, Ultimo NSW 2007, Australia; E-Mail: damien.giurco@uts.edu.au \\ 2 Industrial Design Program, Faculty of Built Environment, University of New South Wales, Sydney \\ NSW 2052, Australia; E-Mail: m.ramirez@unsw.edu.au
}

* Author to whom correspondence should be addressed; E-Mail: johannes.behrisch@uts.edu.au; Tel.: +61-431-128-0-27; Fax: +61-2-9514-4941.

Received: 11 August 2011; in revised form: 14 September 2011 / Accepted: 15 September 2011 / Published: 10 October 2011

\begin{abstract}
Ecodesign offers significant potential to reduce the environmental impacts of products. Whilst some integration of environmental considerations into design occurs in progressive companies when engineering the product, this only represents a small share of the possible design interventions to improve the environmental performance of products. For example, developing new product concepts to fulfill needs in a less environmentally harmful way and considering user related aspects offers a large, currently under-realized potential. This paper identifies industrial design (ID) consultancies as potential agents to tackle this issue on a strategic and operational basis. The extent to which this potential is currently applied was assessed by conducting a content analysis of websites of ID consultancies in Australia, China, and Germany. How ID consultancies represent their ecodesign practice is country-specific. Despite the differences, some ID consultancies in all countries announce and/or show the capability to develop completely new concepts and to influence user related factors to improve environmental performance. This shows their potential to address current shortcomings in ecodesign practice. As ID consultancies embracing that potential still are a minority, further research should be directed to a deeper examination of barriers and stimuli for ID consultancies to take up ecodesign.
\end{abstract}

Keywords: ecodesign practice; industrial design; design consultancies 


\section{The Concept of Ecodesign}

To manage the negative environmental impact of products, a significant effort is put in remedial actions such as waste management, pollution control and cleaning up production and disposal sites. Whilst necessary, such actions alone do not have the potential to reduce the environmental impact of our products to a degree that facilitates a sustainable society [1,2]. Interventions at the design stage of products have a much higher potential to improve their environmental performance [1,3]. These activities are usually termed as ecodesign [3-5]. Interventions to reduce environmental impacts require innovation, which can happen at various levels. Crul et al. classify three different types of innovation: incremental, radical and fundamental [6]. This is to be understood as a scale of innovation, with incremental at one end and fundamental at the other end, rather than three distinct categories. Incremental innovations are most commonly associated with step by step improvements of existing products through redesign processes. By contrast, new product design or even the development of completely new concepts requires radical or fundamental innovation. An example that can be allocated quite far on the radical and fundamental side of the innovation scale is the Better Place project [7], which has developed a new concept to facilitate tomorrow's mobility. In the context of the aim of sustainable development, Manzini and Vezzoli and Crul et al. point out that while incremental innovation is important, only radical and fundamental can sufficiently reduce the environmental impact $[6,8]$.

\subsection{Review of Current Ecodesign Practice}

Several studies have been carried out to evaluate the current uptake of ecodesign in practice [9-11]. The studies indicate that the degree to which the concept of ecodesign diffused into product development practice is country specific. There appears to be some uptake of ecodesign in progressive companies in developed countries $[9,11,12]$. The majority of incremental innovations that facilitate win-win situations for economic and ecological aspects are already realized by these companies [12]. Bas de Leeuw notes in the preface of the book "New business for old Europe" that current ecodesign practice is strongly linked to the engineering phase of the product [13]. Legislation [9], customer demand [11] and internal motivation [14] are frequently mentioned as drivers for ecodesign uptake. There appears to be less uptake of the concept of ecodesign in developing countries [10]. However, in countries like China and Taiwan, which have a strong focus on exporting manufactured goods, the concept of ecodesign increasingly diffuses into the product development process $[15,16]$. One driver for this is the influence of progressive product policies in the countries where the goods are exported to $[10,15,16]$. Additionally, countries like China increasingly release environmental product policies themselves [17]. As in the developed countries, the ecodesign interventions are mainly focused on the engineering phase $[10,15,16]$.

\subsection{Critique of Current Ecodesign Practice}

There is much critique of current ecodesign practice. Partly due to the fact that it never left the engineering phase, a lot of potential remains untapped $[13,18]$. Product engineering happens at a rather late stage of the product design process, where the ability to implement changes is low, compared to 
earlier stages [19]. This not only limits most ecodesign innovations to the incremental level but also the possibility to influence product properties that are not in the focus of engineering. For example, user-related factors like behavior can to a significant degree be influenced by product design and have a major impact on the environmental load of products. Chapman notes that a large share of products that still work get replaced, causing unnecessary environmental impact, only because they are perceived as outdated by the user [20]. Karlsson and Luttropp, highlight that ecodesign is not promoted well enough or made tangible [21]. Due to its engineering focus, most ecodesign activities happen in the background, unrecognized by the final consumer. This also limits the possibility to make ecodesigned products as such attractive and create a demand for them.

It is not clear why the concept of ecodesign has not yet successfully diffused to the practice of other disciplines active in product development. One reason might be that issues tackled by engineers are easy to measure and evaluate and therefore attract more attention than the less tangible issues like user related factors $[22,23]$. Furthermore, companies might favor incremental innovation in the engineering phase as it associated with a lower risk level than fundamental or radical innovation [6,24]. Another reason may be rooted in the fact that the concept of ecodesign emerged from an engineering background and most tools to practice ecodesign are designed for engineers [25]. There is disagreement about the pivotal role of the development of more ecodesign tools as Karlsson and Luttropp note that "The tools in ecodesign are not as important as specification and goal setting early in the product development phases.” [21]. Therefore, it is likely that that stronger agency for ecodesign has to be established in the earlier phases of the product development process where ID consultancies are active.

\subsection{Recommendations for Ecodesign Practice}

To identify ID consultancies as potential change agents, this section reviews recommendations for ecodesign practice.

Roozenburg and Eekels divide the product development process in two main phases [26]:

(1) the product planning phase which determines what will be developed and for what reason;

(2) the strict development phase which works out a plan for doing so.

Both phases are crucial for ecodesign. Once implemented, the ecological goals have to be pursued throughout the whole product development process to find their embodiment in the final product [27]. Ecological considerations should be considered as early as possible in the product development process $[3,19,21,28,29]$. In the product planning phase, the requirements are most flexible and it is easiest to implement changes if necessary. An early integration of ecological considerations not only best facilitates aligning them with other product requirements, but also offers the largest potential to realize innovations on a more radical or even fundamental scale [25,28]. A broad range of strategies have been suggested to reduce the environmental impact of products. A comprehensive list is published by Brezet and Van Hemel [5]. It covers eight main strategies which are divided into 33 substrategies. Behrisch et al. [30] extended the list of strategies with a ninth strategy: "Increasing the attractiveness of an eco-friendly solution”. As making products attractive and desirable is one of the 
core competencies of industrial design, this strategy is likely to be specific to that discipline [21]. The ecodesign strategies are listed in Table 1.

Table 1. Ecodesign strategies*.

\begin{tabular}{ll}
\hline \multicolumn{1}{c}{ Strategy } & \multicolumn{1}{c}{ Sub-strategies } \\
\hline @) ${ }^{* *}$ New concept development & $\begin{array}{l}\text { Dematerialization, shared use of product, integration of functions, functional } \\
\text { optimization of product components }\end{array}$ \\
$\begin{array}{l}\text { Product component level } \\
\begin{array}{l}\text { 1) Selection of low impact } \\
\text { materials }\end{array}\end{array}$ & $\begin{array}{l}\text { Cleaner materials, renewable materials, lower energy content materials, recycled } \\
\text { materials, recyclable materials }\end{array}$ \\
2) Reduction of materials usage & Reduction in weight, reduction in transport volume
\end{tabular}

\section{Product structure level}

3) Optimization of production techniques

Alternative production techniques, fewer production steps, lower/cleaner energy consumption during production, less production waste, fewer/cleaner production consumables

4) Optimization of distribution system

Less/cleaner/reusable packaging, energy-efficient transport mode, energy-efficient logistics

5) Reduction of impact during use

Lower energy consumption during use, cleaner energy source, fewer consumables needed, cleaner consumables, no waste of energy/consumables

\section{Product system level}

6) Optimization of initial lifetime

Reliability and durability, easier maintenance and repair, modular product structure, classic design, strong product-user relation

7) Optimization of end-of-life system

Reuse of product, remanufacturing/refurbishing, recycling of materials, safer incineration

** This strategy has been given the symbol '@’ because it is much more innovative than the seven other strategies 8) Increasing the attractiveness of an eco-friendly solution

*Strategies @ to 7 adapted from Brezet and Van Hemel, 1997 [5], Ecodesign strategy 8 added by Behrisch et al. [30].

They cannot be applied randomly in the hope of an improvement of the environmental performance of the product. To select the "right" ecodesign strategy, an understanding of the product life cycle has to be established [4]. This usually happens with the help of tools like Life Cycle Assessment (LCA). Selecting the appropriate ecodesign strategies and pursuing them in the product development process is termed Life Cycle Thinking (LCT) [11]. As highlighted earlier, current ecodesign practice mainly follows strategies, closely linked to the engineering discipline. Substrategies, aiming at interventions at the user-level like "strong product-user relation", “classic design" or "lower energy consumption during use" (if it relates to a changed user behavior), are scarcely applied in practice [18]. Furthermore, ecodesign innovations mainly happen on the incremental level. Therefore the strategy "new concept development” does not appear to be widely applied as it requires innovations on a more radical or even fundamental level.

The next section will identify ID consultancies as potential agents to comply with recommendations for practicing ecodesign and to address the discussed shortcomings in current ecodesign practice. 


\section{ID Consultancies: Potential Agents for Ecodesign}

Several progressive authors identified the discipline of industrial design as having a high potential to lessen the environmental load of our products [1,25,31-36]. In addition, the current statement of the ICSID (International Council of Societies of Industrial Design) highlights "enhancing global sustainability and environmental protection” as one of the major aims of industrial design [37].

When joining a product development process, designers usually proceed as soon as they can to visualizing or even prototyping different possible solutions [35,38-40] in which they interpret and synthesize the different product requirements. This activity allows testing different possible pathways early in the product development process and reduces risk and uncertainty about them. The learning from this can be used in a strategic way and feed back into the product requirements [41,42]. The impact of this feedback loop can even exceed the product requirements and alter the scope of a project as shown in a case study by Feldman and Boult [43]. This gives designers the potential to influence the product planning phase where ecodesign implementation is crucial.

The discipline of industrial design is specialized in integrating the user perspective into the product development process [36,39,41]. Designers are not only responsible for the aesthetic appeal of the product or its usability but increasingly plan whole user experiences. This understanding of the user perspective puts designer in a good position to help shortcomings in applying user related ecodesign strategies [38].

Despite a high potential to foster ecodesign uptake, two main factors can hinder industrial designers from successfully doing so: their role in the product development process $[25,44,45]$ and a possible lack of appropriate ecodesign support $[25,46]$.

Most industrial designers employed in in-house product development departments, are active in the strict development phase only [25,36]. Conversely, ID consultancies are likely to be in a different position [47]. Weiss observes that ID consultancies increasingly take over strategic roles, providing them with the possibility to directly impact on the product planning phase [41]. This enables ID consultancies to impact more directly on the product planning phase and puts them in a good position to follow the recommendation of early ecodesign implementation.

As highlighted earlier, traditionally ecodesign has a strong engineering focus. In the past, industrial designers have been observed to be hesitant to invest time and effort in gathering the necessary data about a product's life cycle [48] which prevents them from practicing LCT. To make life cycle information more readily available, various new tools have been developed, some of them with a clear non-engineering focus. Lists of representatives of ecodesign tools have been published for example by Luttropp and Lagerstedt [29] and by Schischke and Garaiza [49].

\section{Research Aims}

As noted above, the discipline of industrial design has the potential to integrate ecodesign early in the product development process and to consider user related factors to reduce the environmental impact of products. In particular ID consultancies are identified as promising agents as they potentially influence the strict development phase and the product planning phase. However, it is not clear if only 
some advanced ID consultancies are in such a strategic position or if this is generally the case. In addition, the degree to which ID consultancies take up ecodesign has not yet been clarified.

Therefore, this paper investigates four questions:

(1) Are ID consultancies in a position that enables them to become agents for ecodesign, especially in the product planning phase?

(2) Do they advertise to practice ecodesign and do they show examples for this?

(3) Are there indications that they can contribute to more radical and fundamental innovations?

(4) Do they show examples or state that they influence user related factors to reduce the environmental impact of products?

\section{Methodology}

To gain the necessary insights, a content analysis, after Krippendorff [50], of websites was used on corporate websites of ID consultancies. Corporate websites communicate the company profile and therefore contain information about the company's services and its portfolio [51,52]. As the literature review revealed, country specific differences such as legislation can have an impact on ecodesign practice. Therefore this study was conducted in three different countries with different environmental product policies: Australia, China and Germany. The German legislative framework that impacts on ecodesign is seen as progressive [9], whereas the Australian one gets criticized for not sufficiently supporting ecodesign. It plans to release product policies that potentially positively impact on this shortcoming in 2011 [53]. Following the model of the EU, China has introduced some environmental product policies and is about to release additional ones in 2011 [17]. However, being a major exporter of manufactured goods, environmental product policies such as the one in the EU still appear to be still stronger drivers for ecodesign uptake [16].

It was aimed to analyze at least 100 ID consultancies per country. Their website URLs were collected from representative databases that are freely available on the internet. For all countries, the database of Core77 [54] and the databases of professional design associations were used [55-57]. All the investigated websites had a portfolio and a capability statement. Their focus had to be on industrial design to be included in the analysis. If a consultancy offered other design services such as graphic design, interior design or similar, these areas of the website were excluded from the data collection. The model of Roozenburg and Eekels was used to allocate the role of the ID consultancy in the product development process namely to the product planning phase or the strict development phase. Drawing on the terminology introduced by Bakker [46], ID consultancies that are active in the product planning phase were tilted as strategic and ID consultancies that are active in the strict development phase were titled as operational. As ID consultancies can cover services for both phases, the term holistic was added to classify them. Mapping the ecodesign activities was done in two steps: firstly it was investigated if the ID consultancies showed any environmental awareness; secondly their capability statements and their portfolio were searched for evidence for the ecodesign strategies listed earlier. If further design interventions to reduce the environmental impact of a product were identified, they were captured as additional ecodesign strategies. To investigate if the ID consultancies base their ecodesign decisions on a LCT approach, indications for the use of support LCA were determined. 


\subsection{Limitations of the Chosen Methodology}

The chosen methodology has three limitations that are important to consider when interpreting the results.

Firstly, even though industrial designers are involved in the development of most products, not all products are developed with the help of ID consultancies. Therefore, this study only shows how far ID consultancies themselves take up ecodesign and does not reveal their overall influence on ecodesign uptake.

Secondly, even though several authors highlight that legislative frameworks are important drivers for ecodesign uptake, it is not clear if legislation impacts heavily on the work of ID consultancies. Furthermore, other country specific differences like culture, the education of the designers, the market for ID consultancies or other factors are also likely to impact on ecodesign uptake. It is beyond the scope of this study to fully elaborate these frameworks for each country.

Thirdly, investigating the corporate websites of the ID consultancy limits the available data to the information that the ID consultancy actually reports on their website. This information might not necessarily reflect their actual practice. For example, some ID consultancies might have been involved in successful projects which demonstrate ecodesign, but are not allowed to publish them due to confidentiality obligations. Other ID consultancies might not want their competitors to copy their ecodesign processes and therefore do not describe them in detail on their corporate website.

The study should be seen as mapping current ecodesign activities by ID consultancies, aiming at testing if ID consultancies in the different countries can address shortcomings in current ecodesign practice.

\section{Results}

\subsection{Role of the ID Consultancies}

As shown in Figure 1, in all investigated countries, few ID consultancies focus only on services for the product planning (strategic) phase. Most ID consultancies offer services for the strict development (operational) phase. The share of ID consultancies, supplementing these services with services for the product planning phase and are titled as holistic is similar in Germany and Australia. A greater share of ID consultancies in China than in the other two countries represents themselves as holistic. It is visible for all the three countries that a significant share of ID consultancies has direct influence on the product planning phase and therefore can potentially strategically implement ecodesign.

\subsection{Environmental Awareness}

The highest environmental awareness was found amongst Australian ID consultancies and the lowest amongst Chinese ones. It is surprising that the highest environmental awareness was not found amongst German ID consultancies, especially regarding the progressive legislative framework [9] and the strong stance of green technologies in Germany [58]. However he applied methodology does not allow drawing of definite conclusions for this finding. This could be due to ecodesign compliance being seen as obligatory by German ID consultancies and therefore not needing special mention on the 
websites; or it could also be because German ecodesign more prevalently occurs during the engineering phase and therefore not the focus of activities amongst ID consultancies. This would align well with findings about the current state of the art of ecodesign practice, indicating that most ecodesign interventions are closely linked to engineering $[9,13,18]$. It is surprising that not all ID consultancies who show examples for applied ecodesign strategies in their portfolio announce ecodesign in their capability statement. Furthermore, the announced ecodesign strategies often do not match the applied ones and vice versa. A detailed summary how ID consultancies express their environmental awareness can be seen in Figure 2.

Figure 1. Role of the ID consultancies.

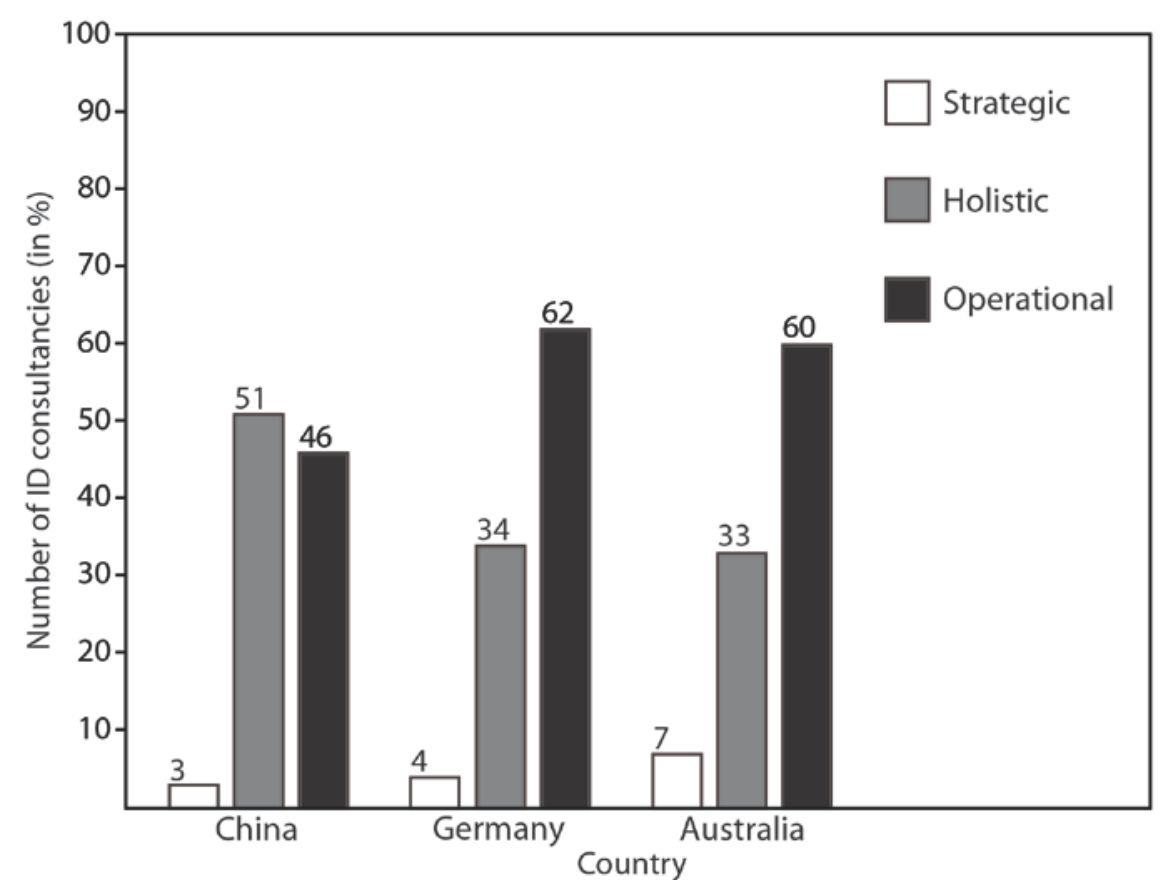

Figure 2. Environmental awareness amongst ID consultancies.

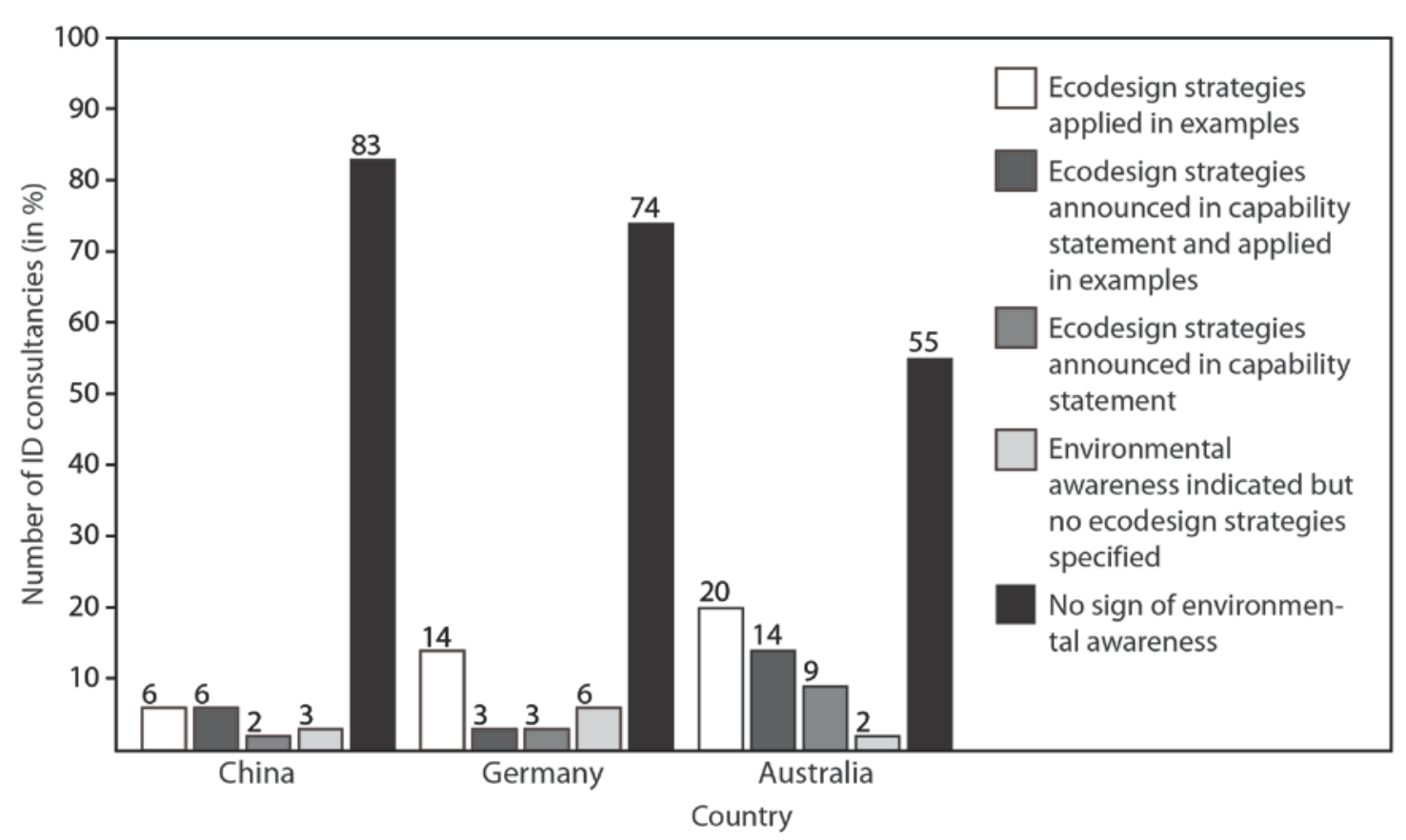


Only on some websites indications were found for the use of support for LCT (See Figure 3). However, that does not mean that the ID consultancies do not practice LCT, as they might not want to reveal the support that they use for their services in the internet.

Figure 3. Life cycle thinking support visible on the ID consultancy websites.

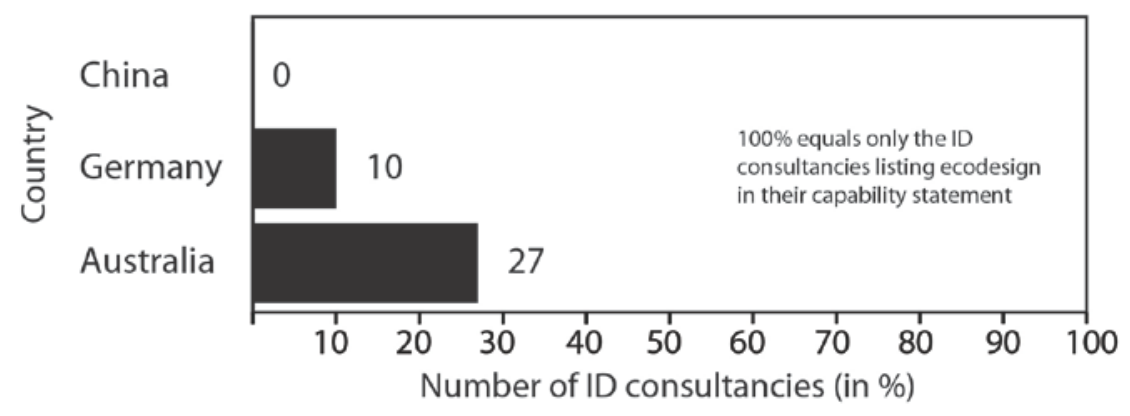

\subsection{Ecodesign Activities}

Figure 4 shows the ecodesign strategies that ID consultancies in the investigated countries announce in their capability statement and/or apply in examples on their website. When interpreting the graph it is necessary to note that $100 \%$ always refers to the ID consultancies that express environmental awareness only. As visible in Figure 2, these numbers are different for each country. In all three investigated countries, ID consultancies cover the whole range of ecodesign strategies suggested by Brezet et al. [5] including the strategy "new concept development”. This can be seen as an indication for the capability of ID consultancies to contribute to innovations on a radical or even fundamental scale. In China and Germany, indications for the application of the additional ecodesign strategy of "making ecodesign more attractive" were found.

In all countries some ID consultancies influence on user related factors for ecodesign. Some quotes from the websites illustrate that: The product "inspire(s) users to keep it for its convenience and high aesthetic value"; "Pleasing design increases the acceptance of this ecofriendly solution"; "personalizing (the product) would encourage people to 'own' and re-use the (product)"; the product "encourages change in users' behavior about environment protection"; the product enables a "strong product-user relation". Despite the potential of considering user related factors and the capability of aiming for more radical or fundamental innovation, these interventions did not represent the majority of announced and/or applied ecodesign strategies.

The popularity of the different ecodesign strategies and therefore the way ecodesign is practiced by ID consultancies varies significantly between the countries. As compliance with legislation rarely gets mentioned by ID consultancies to promote their ecodesign services, it is likely that other country-specific frameworks and factors impact on ecodesign practice of ID consultancies. 
Figure 4. Ecodesign strategies, found on websites of ID consultancies.

\begin{tabular}{l|l|l|l} 
& China & Germany & Australia \\
\hline New concent & & $\square ा$ &
\end{tabular}

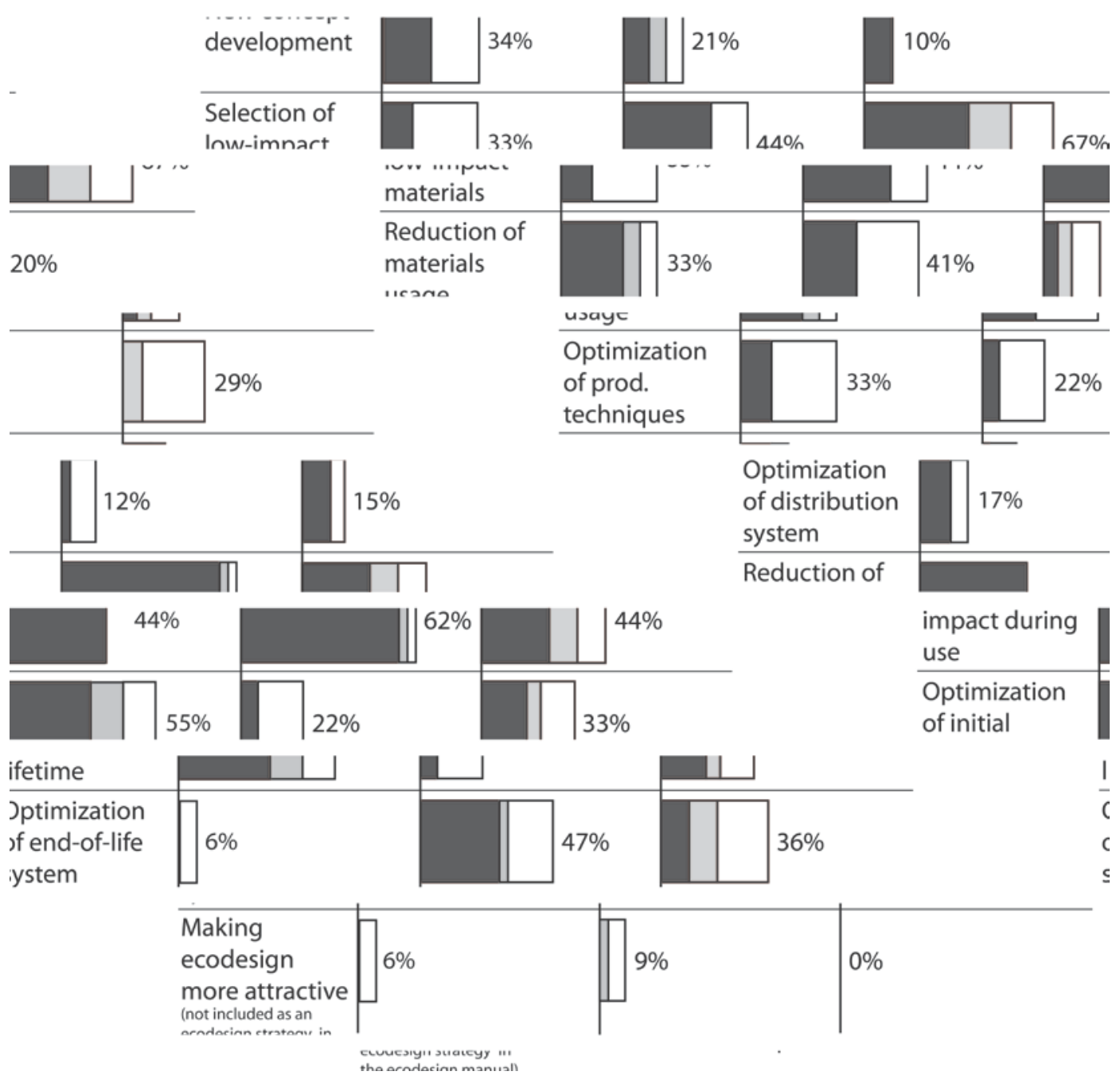

\section{Conclusions}

In each country, a significant amount of ID consultancies represents themselves in a position where they have direct influence on the product planning phase, where it is crucial to implement ecodesign. They therefore are likely to have higher potential to implement ecodesign than industrial designers employed in product development departments. The majority of ID consultancies do not promote ecodesign on their website. In all countries, all ecodesign strategies suggested by Brezet and Van Hemel [5] were announced and/or applied in examples on some websites. Especially the strategy "new concept development" shows the capability of ID consultancies to contribute to radical or fundamental innovation. Some ID consultancies in all countries show capabilities to use their skills in influencing user related factors to follow ecodesign strategies. The study found some evidence for LCT on websites of ID consultancies Germany and Australia. However the methodology did not allow investigating how far LCT actually diffused into the practice of ID consultancies. To find out if ID consultancies base their ecodesign interventions on LCT and thereby assure to select appropriate 
ecodesign strategies requires more in-depth research into the actual ecodesign processes in each country.

Despite these uncertainties, the findings support the assumption that ID consultancies can play a key role in addressing current deficits in ecodesign practice. However, only a minority of ID consultancies appear to make use of that potential in practice. The way ID consultancies practice ecodesign varies from country to country. To gain a better understanding how ID consultancies can unlock their potential for ecodesign, further research in country specific frameworks and the practice of ID consultancies is necessary.

\section{Further Research}

This publication is part of a larger research project investigating the role of ID consulting for ecodesign uptake in a commercial context. The next steps of this research will include conducting online surveys and detailed interviews with ID consultancies and their clients about their experience with ecodesign projects. This will develop a deeper understanding of the actual ecodesign processes conducted by ID consultancies and allow drawing further conclusion about the barriers and enablers for ecodesign in that context.

\section{Acknowledgments}

The authors would like to thank Joseph Louis Tan who conducted the website content analysis of the Chinese websites. The authors furthermore would like to thank two reviewers for their feedback and helpful comments on this paper.

\section{Conflict of Interest}

The authors declare no conflict of interest.

\section{References and Notes}

1. Schmidt-Bleek, F. Wieviel Umwelt braucht der Mensch? MIPS. Das Maß für Ökologisches Wirtschaften; Rainer Klüting Birkhäuser Verlag AG: Basel, Switzerland, 1999.

2. Charter, M.; Tischner, U. Sustainable Solutions: Developing Products and Services for the Future. Greenleaf Publishing: Sheffield, UK, 2001.

3. Tischner, U.; Schmincke, E.; Rubik, F.; Prosler, M. How to Do EcoDesign? Verlag Form: Frankfurt, Germany, 2000.

4. Wimmer, W.; Züst, R.; Lee, K.-M. Ecodesign Implementation: A Systematic Guidance on Integrating Environmental Considerations into Product Development; Springer: Dordrecht, Netherlands, 2004.

5. Brezet, H.; Van Hemel, C. Ecodesign: A Promising Approach to Sustainable Production and Consumption; UNEP: Paris, France, 1997.

6. Crul, M.; Diehl, J.; Ryan, C. Design for Sustainability A Step-by-Step Approach; UNEP: Paris, France, 2009. 
7. Andersen, P.H.; Mathews, J.A.; Rask, M. Integrating private transport into renewable energy policy: The strategy of creating intelligent recharging grids for electric vehicles. Energ. Policy 2009, 37, 2481-2486.

8. Vezzoli, C.; Manzini, E., Design for Environmental Sustainability; Springer: London, UK, 2008.

9. Tukker, A.; Eder, P.; Charter, M.; Haag, E.; Vercalsteren, A.; Wiedmann, T. Eco-design: The State of Implementation in Europe-Conclusions of a State of the Art Study for IPTS. J. Sustain. Prod. Design 2001, 1, 147-161.

10. Lindahl, M. The State of Eco-design in Asian Electrical and Electronic Companies: A Study in China, India, Thailand and Vietnam; AEDE Asia Eco-Design Electronics I Centre for Sustainable Design: Farnham, UK, 2007; p. 160.

11. Mathieux, F.; Rebitzer, G.; Ferrendier, S.; Simon, M.; Froelich, D. Ecodesign in the European Electr(on)ics industry-An analysis of the current practices based on cases studies. J. Sustain. Prod. Des. 2001, 1, 233-245.

12. Stevels, A. Moving companies towards sustainability through eco-design: Conditions for success. J. Sustain. Prod. Des. 1997, 3, 47-55.

13. Tukker, A.; Tischner, U. New Business for Old Europe; Greenleaf Publishing Ltd: Sheffield, UK, 2006.

14. Van Hemel, C.; Cramer, J. Barriers and stimuli for ecodesign in SMEs. J. Clean. Prod. 2002, 10, 439-453.

15. Chen, J.; Shih, L.; Yang, J.; Chen, T. In Eco-design activities in Taiwan. In Proceedings of 4th International Symposium on Environmentally Conscious Design and Inverse Manufacturing, Tokyo, Japan, 12-14 December 2005; pp. 535-538.

16. Chen, P. The WEEE challenge to China. In Proceedings of 4th International Symposium on Environmentally Conscious Design and Inverse Manufacturing, Tokyo, Japan, 12-14 December 2005; pp 532-534.

17. McElwee, C. Environmental Law in China-Mitigating Rish and Ensuring Compliance; Oxford University Press: Oxford, UK, 2011; Available online: http://www.chinaenvironmentallaw.com/ (accessed on 15 December 2010).

18. Fletcher, K.; Goggin, P. The dominant stances on ecodesign: A critique. Des. Issues 2001, 17, 1525.

19. Bhamra, T.A.; Lofthouse, V.A. Making things better-An industrial designer's approach to ecodesign. In Proceedings of D3 Desire, Designum, Design: 4th European Academy of Design Conference, Aveiro, Portugal, 10-12 April 2001.

20. Chapman, J. Emotionally Durable Design: Objects, Experiences and Empathy; Earthscan: London, UK, 2005.

21. Karlsson, R.; Luttropp, C. EcoDesign: What's happening? An overview of the subject area of ecodesign and of the papers in this special issue. J. Clean. Prod. 2006, 14, 1291-1298.

22. Schneider, E. Unchaining the value of design. Eur. Manag. J. 1989, 7, 320-331.

23. Zafarmand, S.; Sugiyama, K.; Watanabe, M. Aesthetic and sustainability: The aesthetic attributes promoting product sustainability. J. Sustain. Prod. Des. 2003, 3, 173-186.

24. Junginger, S. Product development as a vehicle for organizational change. Des. Issues 2007, 24, 26-35. 
25. Lofthouse, V. Investigation into the role of core industrial designers in ecodesign projects. Des. Stud. 2004, 25, 215-227.

26. Roozenburg, N.; Eekels, J. Product Design: Fundamentals and Methods; John Wiley \& Sons Inc: Hoboken, Netherlands, 1995.

27. White, C.; Stewart, E. Aligned for Sustainable Design: An ABCD Approach to Making Better Products; Business for Social Responsibility (BSR): San Francisco, CA, USA, 2008.

28. Giudice, F.; La Rosa, G.; Risitano, A. Product Design for the Environment: A Life Cycle Approach. CRC Press: Boca Raton, Italy, 2006.

29. Luttropp, C.; Lagerstedt, J. EcoDesign and The Ten Golden Rules: Generic advice for merging environmental aspects into product development. J. Clean. Prod. 2006, 14, 1396-1408.

30. Behrisch, J.; Ramirez, M.; Giurco, D. The use of ecodesign strategies and tools: State of the art in industrial design praxis. In Knowledge Collaboration \& Learning for Sustainable Innovation; ERSCP-EMSU: Delft, the Netherlands, 2010.

31. Papanek, V. Design for the Real World: Human Ecology and Social Change; Thames and Hudson: London, UK, 1985.

32. Papanek, V. The Green Imperative: Ecology and Ethics in Design and Architecture; Thames and Hudson: London, UK, 1995.

33. Rams, D. Weniger, Aber Besser; Design + Design: Hamburg, Germany, 1995.

34. Schmidt-Hellerau, K. Jahrbuch des Deutschen Werkbundes; Deutscher Werkbund: Jena, Germany, 1912.

35. Wahl, D.; Baxter, S. The designer's role in facilitating sustainable solutions. Des. Issues 2008, 24, 72-83.

36. Blaich, R.; Blaich, J. Product Design and Corporate Strategy: Managing the Connection for Competitive Advantage; McGraw-Hill: New York, NY, USA, 1993.

37. Definition of Design; The International Council of Societies of Industrial Design (Icsid): Montreal, QC, Canada, 2010; Available online: http://www.icsid.org/about/about/articles31.htm (accessed on 10 November 2010).

38. Young, G. Design Thinking and Sustainability; Zumio: Sydney, Australia, 2010; p. 27.

39. Brown, T.; Katz, B. Change by Design: How Design Thinking Transforms Organizations and Inspires Innovation; Harper Business: New York, NY, USA, 2009.

40. Tennity, M What clients want in consultants. Des. Manag. J. (Former Series) 2003, 14, 10-14.

41. Weiss, L. Developing tangible strategies. Desi. Manag. J. 2002, 13, 33-38.

42. Dubberly, H. How Do You Design? A compendium of Models; Dubberly Design Office: San Francisco, CA, USA, 2004.

43. Feldman, J.; Boult, J Third-generation design consultancies: designing culture for innovation. Des. Manag. Rev. 2005, 16, 40-47.

44. Davis, S.; White, P. Electronic Product Ecodesign Influence; Industrial Designers Society of America: San Francisco, CA, USA, 2004.

45. Ueda, E.S.; Shimitsy, T.; Sato, K. The role of industrial designers in Japanese companies involved in eco-redesign process. In Proceedings of 6th Asian Design International Conference, Tsukuba, Japan, 14-17 October 2003. 
46. Bakker, C.A. Environmental Information for Industrial Designers. Ph.D. Thesis, Technische Universiteit Delft: Delft, The Netherlands, 1995.

47. Mawle, R.; Bhamra, T.; Lofthouse, V. The practice of ecodesign. In Knowledge Collaboration \& Learning fur Sustainable Innovation; ERSCP-EMSU: Delft, The Netherlands, 2010.

48. Hornbuckle, R.; Qualmann, C.; Sutton, T. Are we the tool? In Proceedings of Nordic Design Research Conference 2009, Oslo, Norway, 30 August-1 September 2009.

49. Schischke, K.; Garaizar, M.B. 2009 Update of EcoDesign Tools and Methodologies; Fraunhofer IZM: Berlin, Germany, 2009.

50. Krippendorff, K. Content Analysis: An Introduction to its Methodology; Sage Publications, Inc: Thousand Oaks, CA, USA, 2004.

51. Capriotti, P.; Moreno, A. Corporate citizenship and public relations: The importance and interactivity of social responsibility issues on corporate websites. Public Relat. Rev. 2007, 33, 84-91.

52. Stuart, H.; Jones, C. Corporate branding in marketspace. Corp. Reput. Rev. 2004, 7, 84-93.

53. National Television and Computer Product Stewardship Scheme Web Site. www.environment. gov.au/settlements/waste/ewaste/news/index.html (accessed on 19 November 2010).

54. Core 77 Design Directory Web Site. www.designdirectory.com/?referral=C77navigation (accessed on 15 November 2010).

55. Verbandes Deutscher Industrie Designer Web Site. www.vdid.de/index_vdid.html (accessed on 18 July 2010).

56. Design Institute of Australia Web Site. www.dia.org.au/ (accessed on 18 July 2010).

57. Industrial Design China Web Site. www.3d3d.cn/info/sjgs/ (accessed on 20 November 2010).

58. Umweltwirtschaftsbericht 2009; Bundesministerium für Umwelt: Bonn, Germany, 2009.

(C) 2011 by the authors; licensee MDPI, Basel, Switzerland. This article is an open access article distributed under the terms and conditions of the Creative Commons Attribution license (http://creativecommons.org/licenses/by/3.0/). 